\title{
Mitigation of NSC and Alleviate of Magnetic Inrush Currents in Indian Traction System
}

\author{
Gopi Krishna Allaboyena \\ SRM University, School of Engineering \& Technology, Kattankulathur, Chennai 603203, India
}

\begin{abstract}
The running of electrified railways causes many problems in the electric utility systems as the traction is a very duty dynamic load. This causes many power quality problems in the system resulting in malfunction of protective relays, circuit breakers, increment in transformer losses etc... This paper focuses on the mitigation of Negative Sequence Currents (NSC) and how the magnetic inrush currents affect the system. The NSC has been compensated indirectly with reference of harmonics. The corresponding results have been discussed and published using MATLAB/Simulink 2014 software.
\end{abstract}

Keywords: Negative Sequence Currents (NSC), harmonics, transformers, induction machines, power convertors

\section{Introduction}

In the present modern and mechanized era the transportation plays very important role in our daily life. In perception of common man life, railways have been efficient means of transportation. The growth of electrified railways has been proved to be successful solution to enhance the capacity of the public transport. The railways were first driven by the diesel engines but due to the pollution and environment condition railways have been changed to electrified system. But traction being non-linear and dynamic load which introduces large amount of harmonics, sub-harmonics, NSC in to the supply system. These cause many power quality problem, increment in the transformer losses, malfunction of protective schemas and circuit breakers. This paper confines to the effects of NSC, magnetic inrush currents, the mitigation of NSC and the how magnetic inrush current effects the system.

For the compensation of the power quality problems the basic is the selection of traction transformer which is done based on the transformer utilization factors. The special type of the transformers like scot connection or impedance balanced connection or Woodbridge connection type transformer suits the best but implementation of these connections is economically not feasible and these transformers are adopted when the load on the both arms of the transformer are balanced which is impossible condition. In this paper the Y- $\Delta$ with the delta open is used which are selected based on the utilization factors

Generally for the mitigation of NSC, traction power conditioner or railway power conditioners are used. But the RPC cannot be implemented in Indian Power Systems because of usage of age-old power units for power generation and transmission. Static VAR Compensator (SVC) has the capability of compensating the NSC and reactive power but it generates harmonics and reduction of power factor. Installation of SVC for the NSC compensation has limitation of installing on $\mathrm{HV}$ side of the transformer which results in increase in the handling voltage capacity of the system for SVC. SVC has the capability of compensating the NSC and reactive power but it generates harmonics and reduction of power factor. Installation of SVC for the NSC compensation has limitation of installing on $\mathrm{HV}$ side of the transformer which results in increase in the handling voltage capacity of the system for SVC.

\section{Indian Railway Traction Power System}

The traction power system is a very complex network which is a three phase system inside a huge single phase system. For the easy understand of the system, the whole system can be classified in two different systems.

One system is outside the railway engine which deal how the $25 \mathrm{KV} \mathrm{AC}$ voltages is drawn as single phase system from a three phase grid connected utility systems. For traction stretched overhead traction are used.

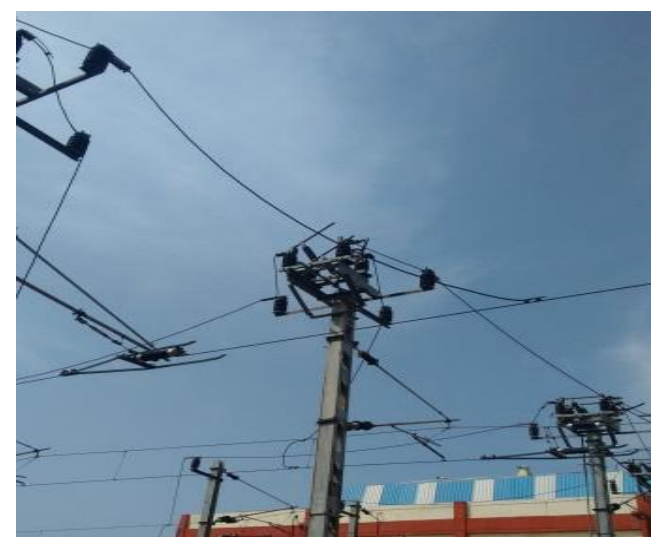

Figure 1: Overhead line for traction

The figure represents the overhead lines from where the $25 \mathrm{KV} \mathrm{AC}$ is tapped and the two parallel projections on the tower are known as dig joints which are responsible for the dead zones in the system.

As traction being a heavy load it is drawn form $220 / 33 \mathrm{KV}$ or $132 / 33 \mathrm{KV}$ normal utility substation to which traction transformer is coupled. Here the Y- $\Delta$ [4] with delta open is used as traction transformer. This transformer is connected to any two phases of the three phase lines and the third phase is utilized for the lighting and other substation loads. Such a 


\section{International Journal of Science and Research (IJSR) \\ ISSN (Online): 2319-7064}

Index Copernicus Value (2013): 6.14 | Impact Factor (2014): 5.611

connection causes an unbalance in the system resulting to NSC and further due to the non-linearity nature of the load it introduces large amount of harmonics and sub-harmonics in the system. For the virtual balancing of the traction load on the power system, the overhead contact wires are supplied from A-B, B-C, C-A at regular intervals (about $20 \mathrm{Km}$ ). This type of permutation in the phases does not change the phase sequence of the system. To avoid the short circuit between the phases during the permutation an un-energized neutral section or dead zone (about $6 \mathrm{~m}$ ) [5] is provided between two consecutive sections of overhead wires energized from different phases.

The other system is inside the engine where the system is three phase system. As the traction motor drive very heavy loads, they are generally three phase asynchronous motors [3]. The voltage that is trapped form the pantograph is directed directly to the $25 \mathrm{KV} / 400 \mathrm{~V}$ single phase transformer which is coupled with convertors and responsible for the control of three phase motors. Thus when the locomotive passes through the dead zone the transformer undergoes switching resulting in magnetic inrush currents in the system.

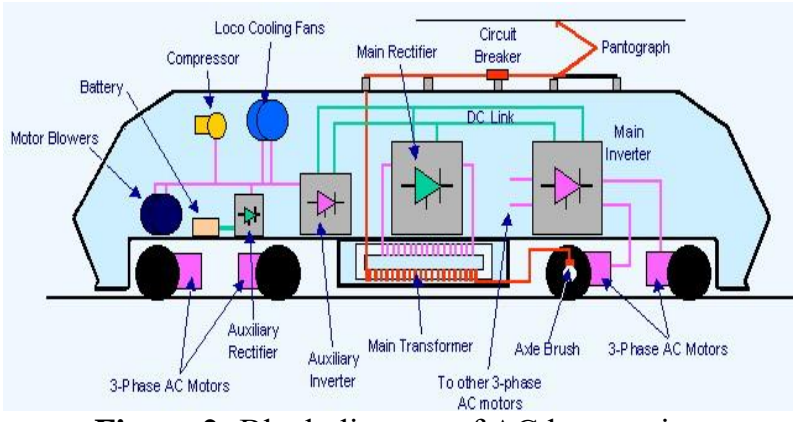

Figure 2: Block diagram of $\mathrm{AC}$ locomotive

This paper confines to mitigation of negative sequence currents and performance of the locomotive with respect to magnetic inrush.

\section{Compensation Theory}

\subsection{Compensation of NSC}

Due to the unbalance loading of the traction transformer NSC is introduced in the system. The primary side (utility side) is free from zero sequence currents as the zero sequence currents flows only when there is a ground path and the $\mathrm{Y}$ side has no ground. Thus the utility system is safe from zero sequence. Considering the secondary though zero sequence currents are introduced they will be circulating in the delta connection as circulating currents. Thus on a whole the system is free from zero sequence currents.

The NSC is mitigated with the reference of the harmonics. Harmonics are integral multiples of fundamental frequencies. Some of the harmonics account to NSC. Thus by compensating harmonics in the system the NSC can be compensated to great extent. By definition harmonics are integral multiple of fundamental frequency. In any system the even order harmonics do not show any effect on the system as all ever order harmonics cancels out each other. All odd order harmonics affects the system and the lower order harmonics are more predominant. Due to integral multiplication to the fundamental, positive negative and zero sequences currents are introduced in the system.

Table 1: Harmonics and sequence relation

\begin{tabular}{|c|c|c|c|c|}
\hline \multirow{3}{*}{ Fundamental } & $\begin{array}{c}\mathrm{A} \\
\end{array}$ & $\begin{array}{c}\mathrm{B} \\
120\end{array}$ & $\begin{array}{c}\mathrm{C} \\
240\end{array}$ & $\begin{array}{c}\text { ABC } \\
\text { Positive } \\
\text { sequence }\end{array}$ \\
\hline \multirow{3}{*}{$3^{\text {rd }}$ harmonic } & $\mathrm{A}^{\prime}$ & $\mathrm{B}^{\prime}$ & $\mathrm{C}^{\prime}$ & \\
& 0 & 360 & 720 & No rotation \\
& 0 & 0 & 0 & \\
\hline \multirow{3}{*}{$5^{\text {th }}$ harmonic } & $\mathrm{A}^{\prime}$ & $\mathrm{B}^{\prime}$ & $\mathrm{C}^{\prime}$ & $\mathrm{CBA}$ \\
& 0 & 600 & 1200 & Negative \\
& 0 & -120 & -240 & Sequence \\
\hline \multirow{3}{*}{$7^{\text {th }}$ harmonic } & $\mathrm{A}^{\prime}$ & $\mathrm{B}^{\prime}$ & $\mathrm{C}^{\prime}$ & ABC \\
& 0 & 840 & 1680 & Positive \\
& 0 & 120 & 240 & Sequence \\
\hline \multirow{2}{*}{$9^{\text {th }}$ harmonic } & $\mathrm{A}^{\prime}$ & $\mathrm{B}^{\prime}$ & $\mathrm{C}^{\prime}$ & \\
& 0 & 1080 & 2160 & No rotation \\
& 0 & 0 & 0 & \\
\hline
\end{tabular}

The above table shows the relation between harmonics and sequences. Harmonics which rotates with the same sequence as the fundamental $\left(1^{\text {st }} 7^{\text {th }} 13^{\text {th }} 19^{\text {th }}\right.$ etc...) are known as positive sequence. Harmonics which rotates opposite to the sequence as the fundamental $\left(5^{\text {th }} 11^{\text {th }} 17^{\text {th }} 23^{\text {th }}\right.$ etc...) are known as negative sequence. Harmonics which do not rotate (triplet harmonics) at all are zero sequence. The system is safe from the zero sequence and the negative sequence is to be suppressed. The presence of negative sequence increases the heating losses in the system and may results in formation of hot spots in the machine windings (transformer or motor). Thus by suppressing the harmonics the negative sequence can be suppressed to a greater extent. Here the negative sequence which is introduced due to unbalance and harmonics is mitigated by harmonic suppression and by negative feedback loops.

During balanced condition sum of the phase currents is zero.

$$
\begin{aligned}
& I_{a}+I_{b}+I_{c}=0 \\
& I_{q}+I_{d}+I_{o}=0
\end{aligned}
$$

But during the unbalanced the sum of the phase currents or phase voltages are never zero.

$$
\begin{aligned}
& I_{a}+I_{b}+I_{c} \neq 0 \\
& I_{q}+I_{d}+I_{o} \neq 0
\end{aligned}
$$

The difference in the currents which is creating the unbalance is negatively fed back from the stator end of the motor through controllers which reduces the unbalancing nature in the currents.

\subsection{Effects of Inrush Currents:}

The magnetic inrush currents are the instantaneous magnitude on the current during the energization of the core in a machine. The magnetic inrush currents come in to the picture when a machine is switched on after a long time or after clearing the faults. Generally the occurrence of the inrush currents depends on the burden on the machine. But in traction system when the locomotive passes from the dead zone the transformer undergoes frequent energization and de- 


\section{International Journal of Science and Research (IJSR) \\ ISSN (Online): 2319-7064 \\ Index Copernicus Value (2013): 6.14 | Impact Factor (2014): 5.611}

energization but this do not introduce huge amount inrush in the system because during this dead zone though the machine is not completely off and thus the burden on the transformer is very low when compared to normal systems.

\section{Simulation and Results}

In order to verify the proposed compensation method and theoretical analysis a simulation is carried out using [3] MATLAB/Simulink.

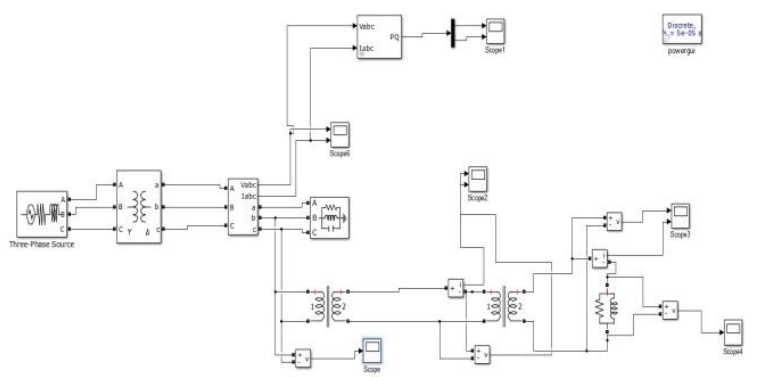

Figure 3: $25 \mathrm{KV}$ AC line form a Utility substation

The above model describes how the $25 \mathrm{KV}$ overhead contact wires are taken form a from grid connected utility substation.

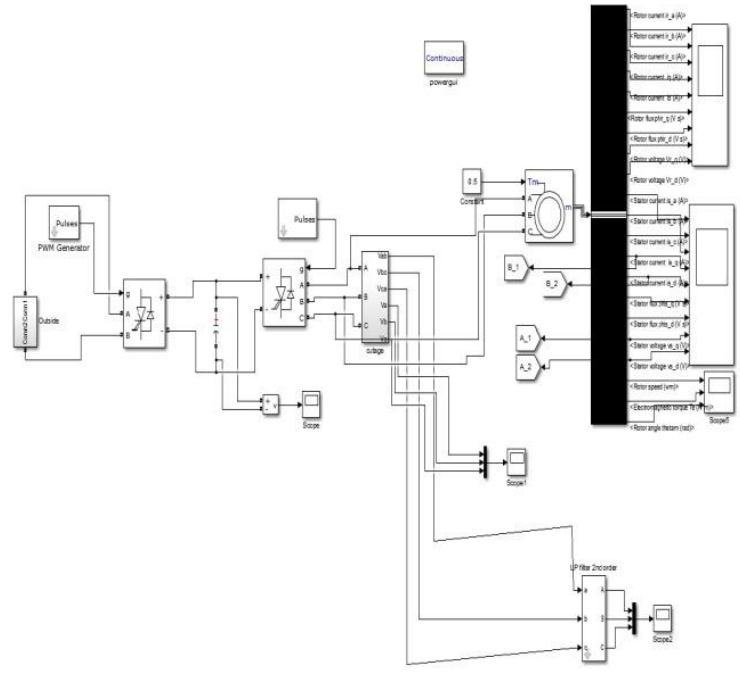

Figure 4: Model of a Locomotive engine

The above block diagram describes the modeling of the system that is inside the locomotive engine. The $25 \mathrm{KV}$ single phase ac voltage that is tapped from the contact wires is fed directly to the $25 \mathrm{KV} / 400 \mathrm{~V}$ transformer whose secondary is coupled to converter inverter. The rectifier and inverter are connected back to back through a capacitor which acts as filter and also maintain dc link between the both. As locomotive is a heavy load, asynchronous induction motor is used to drive the system. The motor here is so designed that is run as variable set speed motor and it is run at $80 \%$ of its full speed. If it is run as full speed then the harmonics which are introduced in the system due to non-linearity nature of the load may affect the performance of the system. To avoid such a condition it made to run as set speed motor, where by the time harmonics effects the system they are damped out due the compensation technique employed and rest are damped to zero when the locomotive pass through dead zone.
The NSC can be suppressed by increasing the driving capacity of the inverter by implementation of multi-level inverter. But implementing such a scheme has limitation of multi souses which is not economically and technically feasible in the system. Thus NSC is mitigated by negative feedback of the stator end parameters to the inverter through a controller. This improves the stator and rotor currents of the motor which results in the improvement of flux distribution on both rotor and stator side.

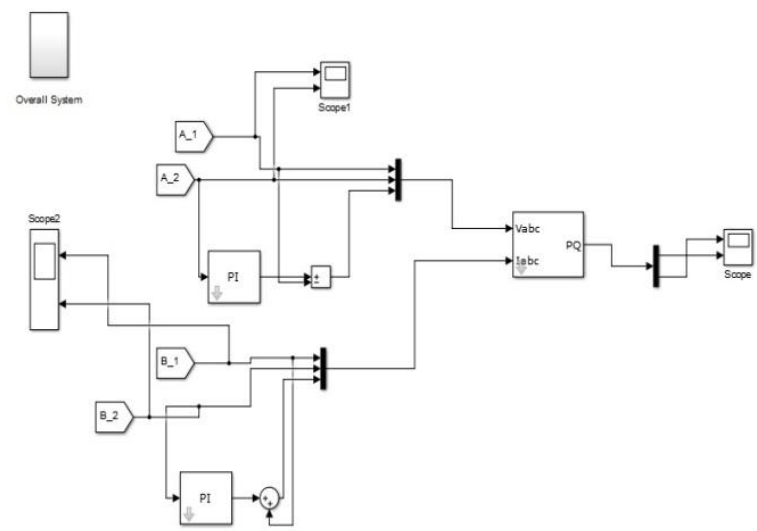

Figure 5: Block Diagram of Feedback Loops

The above block diagram shows the negative feedback loops through the controllers which improvers the flux distribution on stator and rotor. The simulation results shows that by implementing the proposed concept the distortions in the currents is reduced and flux distribution is almost sinusoidal. For the further conformation motor dynamic characteristic also have been discussed. The simulation results which shows the ideal performance of the motor as depicted below.

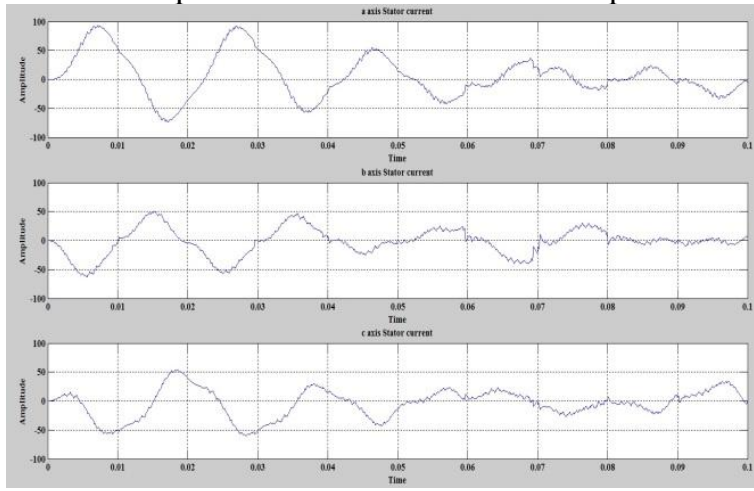

Figure 6: Stator Currents with respect abc phases

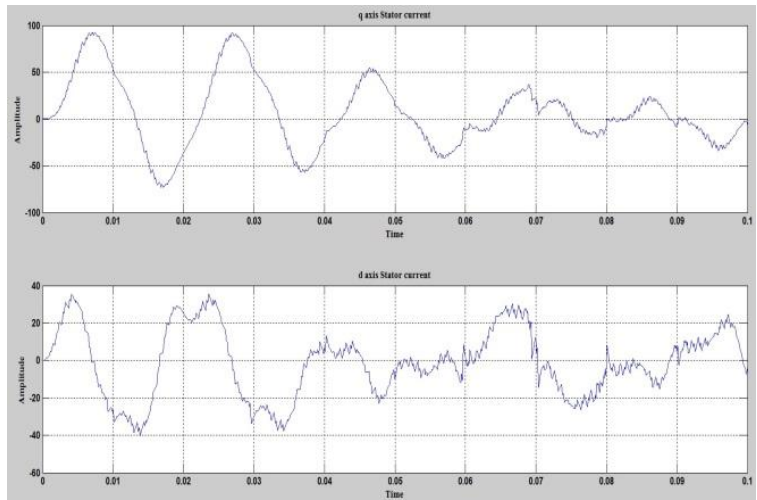

Figure 7: Stator Currents with respect to $\mathrm{q}$ and $\mathrm{d}$ axis 


\section{International Journal of Science and Research (IJSR) \\ ISSN (Online): 2319-7064}

Index Copernicus Value (2013): 6.14 | Impact Factor (2014): 5.611

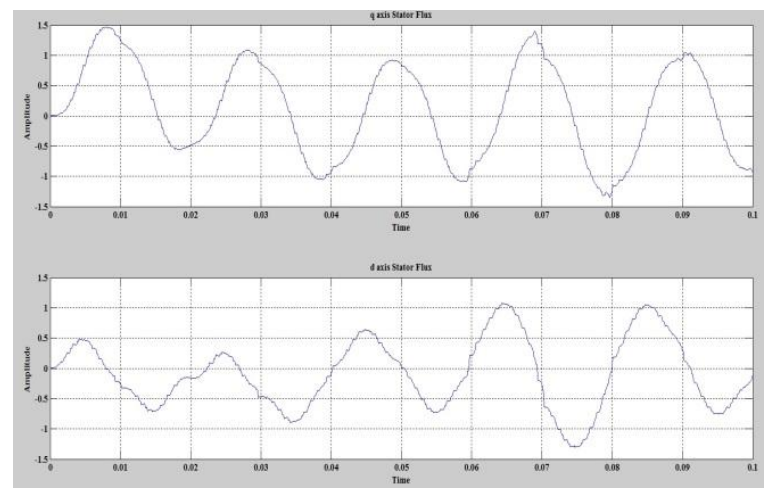

Figure 8: Stator magnetic flux distribution on $\mathrm{q}$ and $\mathrm{d}$ axis

The figure 6 and 7 shows the abc phase and qd axis currents respectively. It is clearly visible that the currents distributions in both the domain is sinusoidal. The amplitude is quite high during the starting which is due the reason that machine draws high current during starting condition. Figure 8 shows the magnetic flux distribution on stator side which is purely sinusoidal. The sinusoidal nature of the current and magnetic flux waveforms represents that there is no flaw stator side. The same holds good for rotor side.

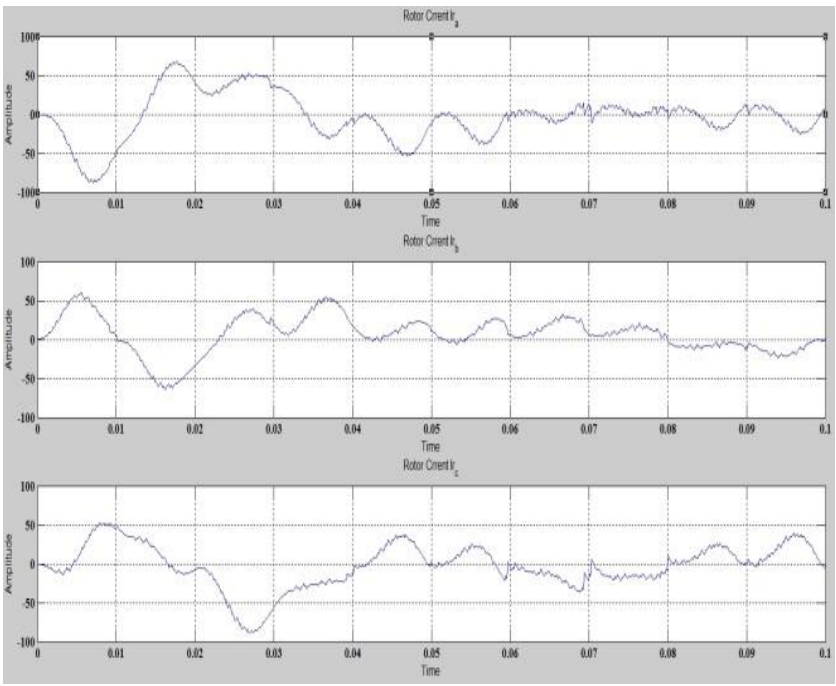

Figure 9: Rotor Currents with respect to abc phases

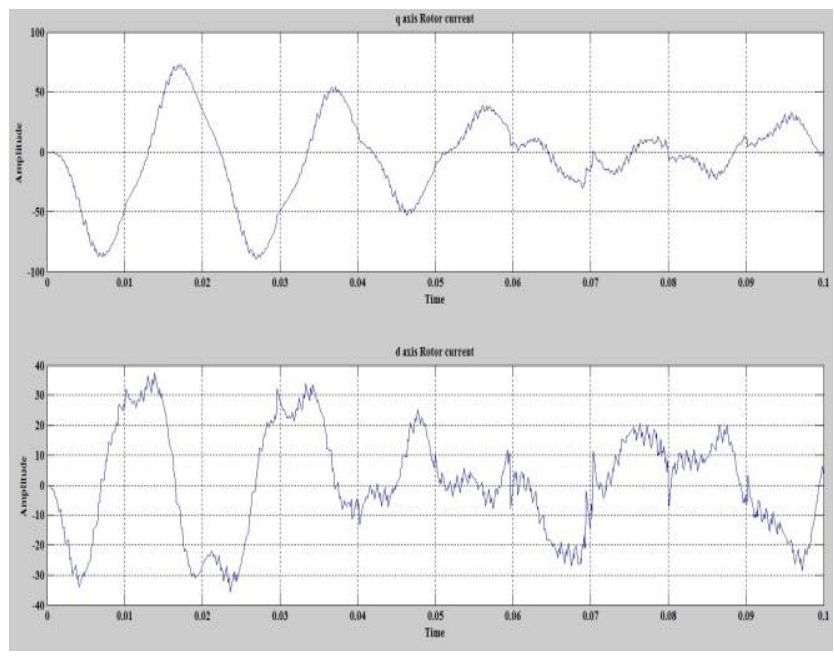

Figure 10: Rotor Currents with respect to $q$ and $d$ axis

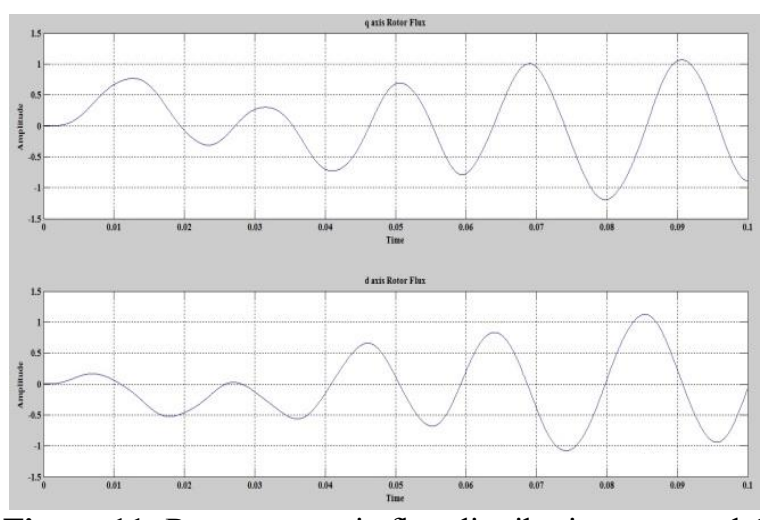

Figure 11: Rotor magnetic flux distribution on $\mathrm{q}$ and $\mathrm{d}$

The figure 9 and figure 10 represents the rotor side currents with respect to abc phases and qd axis respectively. Comparing these with that of stator side the waveform will be perfectly opposite in phases which is due to the reason induction which is the basic working principle of the induction machines. Focusing our vision on stator and rotor currents there are some disturbances which are due to harmonics and unbalances. But when these currents are fed back to the arington through negative feedback controller, the flux distribution on both stator and rotor side becomes pure sinusoidal which makes the machine to run without any difficulties.

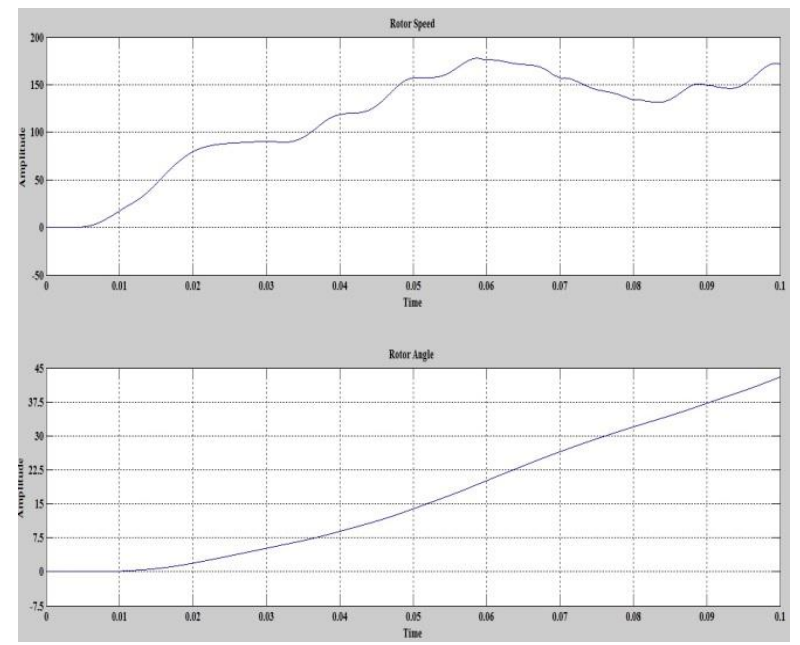

Figure 12: Speed and Rotor angle

The above graphs show the rotor speed and rotor angle variations curves respectively. As discussed earlier, the machine that is being used to drive the locomotive is variable set speed motor the speed curve increases in steps and the sudden decrement represents to the condition, when the locomotive pass through dead zone.

The other curve defines the rotor angle characteristic which is almost linearly increasing. As the speed increases the load angle also increases which as basic working principle of induction machine. For traction system the load angle confines to the range of 30 degrees to 45 degrees which is normal operation range for an induction machine. Thus when the locomotive motor is controlled by inverter with negative feedback control it mitigates the NSC and harmonics, without effecting the utility power transmission. 


\section{International Journal of Science and Research (IJSR) \\ ISSN (Online): 2319-7064}

Index Copernicus Value (2013): 6.14 | Impact Factor (2014): 5.611

While passing through dead zone the transformer inside the locomotive undergoes de-energization and energization which result in magnetinc inrush current in the system. But as the motor which is a burden to the transformer do not stops completely the burden on transformer will be less (almost negligible). But still the introduces inrush can be reduced by connecting fast switching resistor [5].

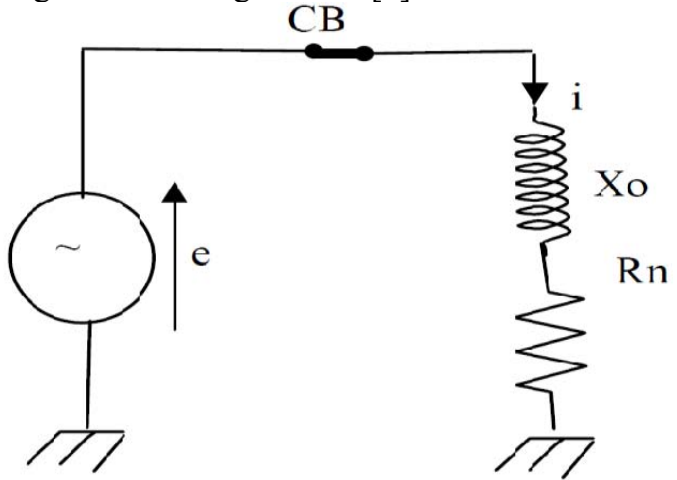

Figure 13: Transformer equivalent circuit for Inrush mitigation

The above circuit represents the equivalent circuit diagram for mitigation of inrush currents. The inrush can be reduced by the external resistance. The overall current passing through circuit is given by [5]

$$
i=\frac{E \sin (\omega t+\delta-\phi)}{\sqrt{R_{n}^{2}+X_{0}^{2}}}-\frac{E \sin (\delta-\phi)}{\sqrt{R_{n}^{2}+X_{0}^{2}}} e^{\frac{-R_{n} t}{L_{0}}}
$$

The total resistance $R_{n}=R_{a}+R_{e}$ (external resistance) and $\mathrm{R}_{\mathrm{a}}<<\mathrm{R}_{\mathrm{e}}$ total resistance $\mathrm{R}_{\mathrm{n}}=\mathrm{R}_{\mathrm{e}}$. The second term of the total current is a dc decaying component which may cause the transformer to saturate and $\mathrm{L}_{0}$ becomes very low. As $\mathrm{L}_{0}$ (saturated) $<<\mathrm{R}_{\mathrm{n}}$ the inrush current mainly depends on $\mathrm{R}_{\mathrm{n}}$ The resistance $R_{n}$ which undergoes fast switching action when the inrush currents are introduced in the system. The design and selection of that resistance should be so done that it should be so high to suppress inrush currents and on the other hand the resistance should be so high that it account losses to the system.

Assuming $\mathrm{L}_{0}$ to be very low the external resistance can be designed using the formula $R_{e} \approx \frac{K V^{2}}{M V A}$ where MVA and $\mathrm{KV}$ are the power and voltage rating of the transformer. This switching of the resistor can be done with the help of fast switching power electronic circuits that are implemented by optical fiber synchronous pulse triggering.

\section{Conclusions}

In this paper, the compensation theory that was adopted aids the system to mitigate NSC, harmonics and shows how harmonics account for sequence currents and their suppression. Though traction power system is not using high profile power electronic devices the NSC and harmonics have been mitigated by implementing negative feedback loops. Also PI controller is used for feedback which damp outs the NSC and aid in maintain and stabilize the DC-link capacitor voltage between rectifier and inverters. Theses simulation results have conformed and validity of theoretical analysis.

\section{References}

[1] Iman Maghsoud, Alireza Ghassemi, Siamak Farshad and Seyed Saeed Fazel, "Current Balancing, Reactive Power and Harmonic Compensation Using a Traction Power Conditioner on Electrified Railway Traction", $3^{\text {rd }}$ international conference on Power Systems, December 2009, $27-29$

[2] C. Wu, A. Luo, J. Shen, F. Ma,S. Peng "A Negative Sequence Compensation Method Based on a TwoPhased Three-Wire Converter for a High-Speed Railway Traction Power Supply System," IEEE Trans. Power Electron. vol. 27, no.2, Feb. 2012, pp. 706-717

[3] Shubhra "MATLAB/Simulink Based Model for Electric Traction Drive", International Journal of Engineering Research and Technology, Vol 3 May 2014.

[4] M. Kalantari, M. J. Sadeghi, S.Farshad, S.S. Fazel, “ Modeling and Comparison of Traction Transformers Based on the Utilization Factor Definitions" International Review on Modeling and Simulations (I.RE.MO.S.), vol.4, no.1, Feb 2011, pp 342-351

[5] K P Basu, Stella Morris "Reduction of Magnetizing Inrush current in Traction Transformer'” DRPT2008 6-8 April 2008 Ninjing China.

[6] Technical Specification for 66/11 KV 15 MVA Transformer With on load tap changer for main receiving station (Indian Railways).

[7] Traction Installation Directorate, Government of India, Ministry Of Railways

[8] A book "Railway Electrification Systems \& Engineering" By Sheilah Frey

[9] Chef Electrical Engineer, Loco Sheds, Kazipet Warangal.

[10]Chef Electrical Engineer, Loco Sheds, Lalaguda Hyderabad.

[11] Chef Electrical Engineer, Testing Unit, Vidyuth Control Systems PVT. LTD Hyderabad.

[12] Electric Traction System website [online], Available: http://www.iffca.org

\section{Author Profile}

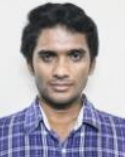

Gopi Krishna received the B. Tech in Electrical \& Electronics Engineering from Amrita University in 2012 and post-graduation M. Tech degree majoring in Power Systems Engineering from SRM University in 2015. He has worked on Indian Traction Railway Systems. His major areas of interest are traction electrification, power systems economics, power quality, electromagnetic transients, overhead transmission lines and underground cable systems. 